\title{
QUESTÃO SOCIAL E QUESTÃO URBANA: laços imperfeitos
}

\author{
Anete B. L. Ivo*
}

\begin{abstract}
O artigo discute a relação problemática entre questão urbana e questão social, desde os estudos clássicos aos dilemas contemporâneos. Recorrendo a autores franceses, este ensaio tematiza a crise das cidades como a expressão aguda da questão social contemporânea. Apresenta a passagem das abordagens clássicas de classe social sobre a estruturação urbana, que orientaram os estudos urbanos dos anos 60-70; as desregulações dos anos noventa, que produziram processos de dessocialização social; e o paradoxo da visão gerencialista da cidade, afastada da dimensão de redistribuição do Estado social. Analisa a polarização urbana através das noções de exclusão, da underclass e da periferização nas cidades e conclui mostrando como o território questiona o Estado e a sociedade através de uma cultura da violência urbana cotidiana. Ao final, esclarece que o desafio não se restringe às relações mercantis, ou a uma política da ordem, mas diz respeito à política e às condições de a "cidade" produzir "sociedade".

PALAVRAS-CHAVE: questão urbana, questão social, segregação urbana, pobreza, conflitos sociais.
\end{abstract}

A relação entre questão urbana e questão social tem sido explorada historicamente por diferentes autores. Essas questões dizem respeito à utopia do "viver juntos" nas modernas sociedades urbano-industriais e às formas de solidariedade e proteção que se constituem na base do tratamento da questão social, sobre uma realidade social marcadamente desigual. Ambas as questões têm acompanhado os fundamentos sociológicos da modernidade sobre o vínculo social, as formas de integração social, coesão social e cidadania, em toda a sua formação. O que estabelece essa relação são as implicações da questão social sobre o território, ou melhor, como as formas de viver, trabalhar, produzir e reproduzir impactam sobre um dado território, na forma de segregação, periferização etc., qualificando a natureza da questão social e as formas de sociabilidade urbanas. Isso não significa

* Doutora em Sociologia, professora do Mestrado de Políticas Sociais e Cidadania da Universidade Católica do Salvador e do PPGCS da Universidade Federal da Bahia. Pesquisadora associada ao Centro de Recursos Humanos - CRH - Faculdade de Filosofia e Ciências Humanas Universidade Federal da Bahia.

Estrada de São Lázaro, 197, Federação. Cep: 40.210-730. Salvador - Bahia - Brasil. anetivo@ufba.br. apenas um exercício mecânico de "localização espacial" do social, aqui entendido como sociedade, mas supõe entender as variáveis do território e do espaço como elementos intrínsecos à formulação da "questão social" clássica e também a sua complexidade hoje: como o processo de hierarquização social e as desigualdades se expressam sobre a morfologia urbana, sobre a acessibilidade dos mais pobres às condições de moradia, trabalho e serviços públicos.

Desde A riqueza das nações, Adam Smith (1776) oferece um campo conceitual dessa relação, orientando a representação filantrópica, estética e, ao mesmo tempo, repressiva da pobreza, particularmente pelo processo de urbanização das sociedades industriais. A interpretação de Smith, sobre a "massa de homens sem propriedade, vista como o(s) inimigo(s) da ordem pública”, expressa um tipo de representação até hoje prevalecente, que articula o processo de empobrecimento em massa que acompanhou a constituição dos mercados de trabalho capitalista a uma visão repressiva da pobreza urbana ou à ideia de uma ordem social regulada pelos proprietários. 
Se o adensamento populacional e a organização do trabalho fabril constituíram elementos estruturantes das cidades modernas no século XIX, no plano político a cidade se articula ao âmbito do público, já que é lócus da "civitas" e da "respublica", o que torna possível a convivência e o intercâmbio, o encontro e o diálogo entre sujeitos com interesses diversos e contraditórios (Sjoberg, 1960; Mumford, 1961;Weber, 1982 apud Duhau, 2001, p. 41). A relação entre cidade e "espaço público" constitui, portanto, outra dimensão importante para uma sociedade fundada no contrato social. "Nestes espaços instauram-se possibilidades de ação pela presença coletiva dos atores sociais e pelo registro dessa presença dramatizada em espetáculo.” (Bresciani, 2002, p. 30).

No século XIX, a questão social emerge das contradições e do debate entre socialistas e liberais, quando os primeiros questionam o caráter formal das liberdades políticas do liberalismo e os limites da autonomia e da liberdade pregados pelo individualismo liberal: "será que o indivíduo que não come e não dispõe de meios para ganhar a vida é verdadeiramente livre?", indagam os socialistas. A essa questão os liberais europeus responderam com um conjunto de mediações institucionalizadas do "direito de obter do Estado, por leis sociais, o mínimo de recursos que torne possível uma vida decente, no nível tolerável da riqueza coletiva." (Cf. Aron, 1969). Segundo Aron, esses direitos sociais não se opõem ao direito-liberdade, mas são condições para o seu exercício, ou seja, eles condicionam a liberdade política. Nesse sentido, as políticas e os direitos sociais constituem-se em mediações institucionais que visam a assegurar a cada um as condições materiais de vida, permitindo a cada cidadão exercer seus direitos sociais e cívicos no âmbito do Estadonação.Éno âmbito desse debate e tendo em vista as condições objetivas da urbanização e os riscos inerentes às novas condições de reprodução social dos trabalhadores nas áreas urbanas que a "questão social" se mescla com a "questão urbana", em seus desdobramentos quanto aos mecanismos de formação de uma solidariedade nacional e uma responsabilidade pública operadas pelo Estado.
Assim, os conflitos resultantes da industrialização, que tiveram como ator principal a formação do operariado em classe e, por outro, a ordem republicana e liberal assentada no princípio da "igualdade", estruturam a formulação da questão social no âmbito das sociedades modernas urbano-industriais, estabelecendo a base para a compreensão problemática entre cidade, questão social e espaço público (Ivo, 2005). Do mesmo modo, é no campo tenso das transformações contemporâneas do mercado de trabalho e no papel redistributivo do Estado social, bem como da emergência de novos atores no encaminhamento dos conflitos sociais e urbanos, que se rediscute a questão social sobre o tecido urbano.

As metrópoles latino-americanas, convertidas em centros industriais, receberam a imigração massiva e viram crescer a classe trabalhadora, cuja presença se manifestou, no espaço físico das cidades, em diversas formas de moradia urbana precarizadas, subúrbios populares carentes, aos quais, nas décadas de 70-80, o Estado respondeu com programas estatais de urbanização popular. A realidade dessa época expressava a "convergência de uma modernização inconclusa no sentido de ter integrado até certo ponto [...] as novas massas urbanas no mercado de trabalho, mas de modo muito limitado em termos da cidadania política e social." (Cf. Duhau, E. e Girola, 1992). A modernidade das cidades latino-americanas inspirou-se em modelos europeus, mas implantou apenas parcialmente e de forma incompleta os dispositivos de um Estado de Bem-estar social.

A integração dos países latino-americanos no curso da mundialização da economia e da reestruturação produtiva dos anos oitenta, no entanto, afetou gravemente as condições de reprodução do trabalho e dos trabalhadores no espaço urbano, dado o processo de desindustrialização, empobrecimento das classes médias e trabalhadoras, desemprego, precarização e vulnerabilidade dos postos de trabalho, bem como adensamento das camadas populares em áreas de residência precária. À pobreza estrutural agrega-se agora um processo de dessocialização de imensas camadas de 
famílias trabalhadoras e o empobrecimento de setores médios, além da precarização de trabalho no núcleo de trabalhadores assalariados, com repercussões sobre as condições de vida de suas famílias.

Esse quadro, que resulta das políticas de ajuste e desregulação do Estado social nacional, tem efeitos desagregadores sobre o padrão redistributivo de bens e serviços urbanos ${ }^{1}$ nas sociedades de países latino-americanos e sobre as condições de moradia, consumo e reprodução das classes trabalhadoras nesses países. No âmbito da moradia, observam-se ilhas de prosperidade num entorno populacional pobre e adensado, ao qual o poder público tem respondido com políticas de remoção da população para áreas de fronteira urbana, sem infraestrutura adequada. Essas políticas, ao longo do tempo, mostraram-se insuficientes, uma vez que esses bairros, deixados ao abandono, tenderam a degradar-se, sem conseguir sustar o processo de expansão de ocupações precárias. Ou seja, a opção pública pelo caminho da segregação e periferização social colabora para o aprofundamento de diferenças sociais sobre o solo urbano, dificultando a mobilidade desses trabalhadores entre casa e trabalho e o compartilhamento de códigos comuns de convívio, integração e sociabilidade das classes populares nas grandes cidades.

No âmbito da cidadania, essa transição se materializa na articulação imperfeita e contraditória entre a consolidação de um direito público, de um lado, que deu forma à nova República (conjunto de leis que regulamentam a pluralidade de interesses diversificados das distintas classes, cristalizado na Constituição de 88), e, de outro, a desregulação das políticas e dos direitos sociais no âmbito do trabalho que, mesmo incompleta, ${ }^{2}$ representou a principal via de integração e mobilidade social e teve efeitos ampliados de proteção

1 A redução dos investimentos em infraestrutura e a privatização de serviços públicos reduzem o papel do Estado quanto ao caráter redistributivo de bens e serviços públicos, especialmente no período dos anos noventa e início da década dois mil. O governo tem investido na reurbanização de favelas e na recriação de grandes conjuntos habitacionais distantes dos centros urbanos.

${ }^{2}$ No sentido de ser restrita à matriz dos trabalhadores assalariados. sobre as famílias de trabalhadores. ${ }^{3}$

A contradição entre esses dois processos tensiona o papel das cidades como matrizes civilizatórias, gerando, no âmbito da representação e da prática dos atores sociais, uma "noção da cidade" como espaço de crise e conflitos sociais agudizados, aprofundando imensas fraturas e promovendo a segregação social e espacial. (Ivo, 2005)

Exatamente quando se agudiza essa crise urbana, as mudanças institucionais e políticas de reforma do Estado nacional repassam às instâncias subnacionais das municipalidades a responsabilidade pública no encaminhamento das políticas sociais. Essa responsabilidade encontra seus limites na própria desterriorialização dos processos econômicos, que ultrapassa as competências das instâncias locais. Ademais, essa transferência de poder ocorre num contexto de atores sociais urbanos "deprimidos" pelas dificuldades de acesso ao trabalho protegido, restringindo-se, especialmente para os jovens, as possibilidades de mobilidade social, utopia que acompanhou a estruturação da modernidade industrial. A incapacidade de o Estado prover investimentos públicos locais que resultem em melhorias efetivas para as camadas mais empobrecidas e para os próprios estratos médios urbanos e a pulverização do campo da política, com a emergência atores políticos internacionais (ONGs, e organizações internacionais, etc.), alteram as condições do "fazer político".

A política que, em décadas anteriores, se estruturava sob o protagonismo da classe operária e das lutas urbanas por moradia ${ }^{4}$ e pelo "direito à cidade", formando atores sociais na construção de agendas próprias de cidadania, reconverte-se em microarenas de gerenciamento estratégico (governança local) na gestão de questões específicas e pontuais da cidade e da pobreza, mediadas por formas de concertação entre diversos atores na implementação de programas públicos.

${ }^{3}$ Ainda que se reconheça que essa redistribuição operou de forma imperfeita, especialmente nos países da América Latina, permanecendo uma matriz social de enormes desigualdades.

${ }^{4}$ Ver, a esse respeito, a Introdução de Vera Telles e Robert Cabannes no livro Nas Tramas da Cidade, 2006. 
Os mecanismos de "gestão da pobreza urbana”, num quadro problemático entre responsabilidades institucionais e a prevalência do mercado no controle dos bens e serviços públicos coletivos, aprofundam as dificuldades de mediação da política e, ao mesmo tempo, uma maior autonomia da cidade. As pulverizadas arenas voltadas para a "gestão pública" partilhada constituem um campo aberto à pluralidade de interesses, que vão desde atores da velha cultura política, no âmbito local, à ação de megaempresas - que se fortalecem no processo de privatização dos serviços públicos -, com efeitos diretos sobre as condições de atendimento das demandas sociais.

A natureza pragmática e tática desses espaços híbridos de gestão urbana tanto pode produzir uma agenda pública pactuada, como pode, igualmente, transformar-se em espaços de disciplinamento dos segmentos sociais mais frágeis, colaborando para processos de apaziguamento ou captura dos atores sociais organizados, despolitizando a "questão urbana" e a "questão social", num contexto em que a cidadania não se encontra organizada. Ademais, a frágil capacidade de investimento público estimula as parcerias público-privadas, subordinando os municípios, muitas vezes, ao financiamento privado, nem sempre compatível com a prioridade da agenda social (Cf. Ivo, 2000).

Le Galès $(1995)^{5}$ analisa que, enquanto as reformas institucionais dos anos oitenta reforçaram o poder do município, isso ocorre, inversamente, num contexto de declínio do poder das autoridades locais eleitas, em decorrência de um conjunto de fatores: ajuste fiscal; transferências e reformas econômicas; crescimento do poder de organizações privadas; terceirização de serviços, etc. Essas mudanças se expressam em termos de crise de confiança entre os cidadãos ou citadinos e o aparelho do Estado, aparecendo como crise de legitimidade, especialmente das autoridades locais. Ou seja, a crise urbana, articulada à crise social, ambas inseridas num contexto de incertezas e reforma do Estado, tem caráter deslegitimatório para

${ }^{5}$ Referindo-se a processos de urban governance na Inglaterra e na França. as autoridades locais. Qual a capacidade de se recriarem, nas cidades, exatamente no espaço da territorialidade da crise social, os nexos necessários à superação da crise social, no presente? Que efeitos essas mudanças trazem para a sociabilidade e a coexistência urbanas?

Este artigo busca analisar essas questões através de um esforço de demarcar campos temáticos e problemáticos entre a questão urbana e a social no contexto das grandes metrópoles contemporâneas, inferindo dimensões problemáticas para as metrópoles latino-americanas e, especialmente, para o Brasil. Ele tenta desenhar pontos contraditórios de convergência entre o social e o urbano das décadas de oitenta até o presente, com base na literatura francesa contemporânea. Para tanto, retoma, de forma geral, os fundamentos da questão urbana, nos anos sessenta e setenta, em torno da análise de classes no espaço de estruturação urbana. Com base num artigo de Didier Fassin (1996), apresenta o modo como a polarização da "questão social" sobre a estrutura urbana se expressa nas noções de exclusão e de subclasse [underclass], recuperando a contribuição das literaturas francesa e americana. Na terceira parte, discute o deslocamento da responsabilização social para o nível local das políticas e a relação entre o global e o local. Por fim, mostra como as ambiguidades e os dilemas das diversas fraturas nas cidades se expressam na "incivilidade urbana", refletida nas diversas manifestações da violência cotidiana da cidade.

\section{A QUESTÃO SOCIAL ${ }^{6}$ E A QUESTÃO URBANA: algumas contribuições clássicas ao debate}

Observando análises de Donzelot (1999), as reflexões sobre a produção do espaço público ${ }^{7}$ dos anos setenta do século XX, na Europa, questiona-

${ }^{6}$ A noção de "questão social” comporta categorias práticas da ação pública determinadas pela ação de atores políticos. Essas categorias passam a ser tratadas como "coletivos" quando objetivadas a partir de programas específicos das políticas sociais. (Cf. Thomas, H., 1997).

${ }^{7}$ Espaço público refere-se, aqui, à parte do território urbano destinado ao uso comum e de posse coletiva. A rua é o espaço público por excelência. 
vam o espaço urbano a partir das relações problemáticas entre urbanização e industrialização, dispersão urbana, grandes e problemáticos conjuntos habitacionais populares, prevalência do uso do automóvel sobre o transporte coletivo, etc. Os autores da época criticavam o urbanismo funcionalista que, segundo eles, havia inspirado, em anos anteriores, a produção de novas periferias operárias. Autores franceses, como Henri Lefebvre e Manuel Castells, entre outros, criticavam essa subordinação ou funcionalidade dos usos dos espaços urbanos para os investimentos do capital e seus efeitos sobre a qualidade de vida dos seus moradores, questionando a hegemonia das relações mercantis e da produção capitalista na estruturação das cidades. A questão central era: como conciliar os efeitos de uma densificação perigosa da população urbana, atendendo, ao mesmo tempo, aos objetivos do desenvolvimento econômico urbano-industrial? As lutas urbanas dos anos setenta e oitenta se ergueram contra os efeitos perversos dessa racionalidade industrial, dando corpo ao que se chama de "questão urbana clássica”.

Nas sociedades de capitalismo periférico, como o Brasil, os bairros populares dos grandes centros urbanos adensaram as massas de migrantestrabalhadores, que aí chegam em busca de empregos, em espaços improvisados de ocupação irregular, espontânea e em condições precárias em termos de infraestrutura, alimentando a produção industrial e expandindo os limites dessas cidades. A política urbana de habitação popular da década de setenta respondeu parcialmente a essa demanda de moradia através da construção de conjuntos habitacionais de massa.

As lutas urbanas constituíram-se, então, em movimentos de protesto e de demanda social por moradia (no caso das cidades latino-americanas), tendo em vista as condições de reprodução da vida no meio urbano, em torno de problemas vitais como moradia, transporte, acesso a energia elétrica, água e também o custo de vida. Os mecanismos de reprodução social da vida das classes populares, nos aglomerados urbanos, introduziam, portanto, duas dimensões: o direito das classes populares à cida- de, ou seja, à sua reprodução social e, ao mesmo tempo, sua legitimação social sobre o espaço (território) público da cidade. Nesse sentido, constituíram-se como movimentos transclassistas, envolvendo desde elementos da classe operária e da classe média, como segmentos dos trabalhadores informais, constituindo-se num denominador comum dos conflitos resultantes da reprodução cotidiana dos trabalhadores e das classes populares. Assume, portanto, na década de sessenta e setenta, a prevalência de uma abordagem marxista, que enfatiza os determinantes econômicos da reprodução social das classes trabalhadoras (Henri Lefebvre, Manuel Castells e Jean Lojkine ${ }^{8}$ ).

Henri Lefebvre $(1968,1974)$ considerava fundamental o "direito à cidade", ${ }^{9}$ afirmando a superioridade do valor de uso contra o valor de troca mercantil, o qual, para ele, reduzia toda a sociabilidade urbana a uma relação de troca mercantil, submetendo o espaço urbano exclusivamente aos imperativos da produção e do consumo. Manuel Castells (1972), no entanto, considerava que o valor de uso da cidade não é senão a aparência antagônica do valor de troca capitalista. Sua função, em última instância, é a reprodução do processo de acumulação capitalista.

O registro do político, nesse quadro analítico, estrutura-se, portanto, com base na tensão e nas contradições da regulação da força de trabalho para o capital no espaço das cidades. As determinações sociais situam-se, portanto, nas condições do poder de coerção da acumulação sobre as condições e os mecanismos de reprodução da classe trabalhadora na esfera da vida, e menos sobre os mecanismos da sua integração social.

De uma perspectiva distinta, que toma como ponto de partida a formação das subjetividades sobre o espaço público, Richard Sennet (1977), em The fall of public man (O declínio do homem público, 1988), critica a prevalência de valores da

${ }^{8}$ Ver Jean Lojkine, La politique urbaine dans la region lyonnaise, 1945-1972. Paris: Moulon, 1974.

${ }^{9}$ Ver, especialmente de Lefebvre, Le droit à la ville. Paris: Anthropos, 1968; La production de l'espace. Paris: Anthropos, 1974 e La revolución urbana. Madrid: Alianza editorial, 1980, 198p. 
vida privada no mundo ocidental como um fator que acaba esvaziando o sentido da vida pública, ameaçando, consequentemente, as práticas e os valores próprios a uma cidade cosmopolita.

\section{A NOVA QUESTÃO SOCIAL COMO QUESTÃO URBANA}

A reestruturação industrial e a considerada "crise" do Estado de Bem-estar social - expressas no desemprego de massa, nas gritantes desigualdades sociais, nas reorientações das políticas sociais e nas diversas manifestações cotidianas de “incivilidades" - fizeram com que a polarização da “nova questão social”, especialmente nas áreas urbanas, manifeste-se a partir de duas noções básicas no espaço urbano: a dos excluídos, na França, e a dos underclass, nos Estados Unidos. Tais noções conformam dois conjuntos históricos de representações sociais e políticas sobre o fenômeno da pobreza contemporânea, os quais resultam também em soluções distintas para ambas as sociedades. Retomo, aqui, o texto de Didier Fassin, Exclusion, underclass, marginalidad (1996), que faz uma recuperação analítica dessas noções e suas implicações políticas. ${ }^{10}$

Na década de setenta, a sociedade francesa rendeu-se a uma constatação: a pobreza persiste, apesar do crescimento econômico. Nesse contexto, a noção de exclusão aparece para designar os inadaptados sociais (deficientes físicos, pessoas inválidas, doentes mentais, crianças abandonadas, menores delinquentes, suicidas, alcoólatras), enfim, indivíduos marcados por dificuldades de sociabilidade ou a-sociais. A esses também se juntavam outras categorias, como vagabundos, antigos delinquentes, prostitutas que não conseguiam encontrar trabalho, e também milhares de famílias das bidonvilles ${ }^{11}$ - que não encontravam trabalho e vivi-

10 A respeito da noção de underclass, ver o texto introdutório de Paul Peterson "The urban Underclss and the Poverty Paradox" no livro The urban underclass, organizado por Christopher Jenks e Paul Peterson, 1991.

${ }^{11}$ Bidonvilles - aglomerações populares precárias, que apresentam falta de higiene, onde vivem as pessoas mais miseráveis (Cf. Micro-Robert, 1980). am de expedientes. (Cf. Lanoir, 1974, p. 27-28). Ou seja, essa noção abrangia, sob uma mesma designação, pessoas com diferentes condições sociais.

Considerar alguém na condição de inadaptado, para Lanoir ${ }^{12}$ (1974), significava defini-lo como aquele que exigia cuidados do outro ou da coletividade:

Dizer que uma pessoa é inadaptada, marginal ou a-social é simplesmente constatar que, na sociedade industrializada e urbanizada do final do século XX essa pessoa, em razão de uma enfermidade física ou mental, do seu comportamento psicológico ou de ausência de formação, é incapaz de prover suas necessidades, exige cuidados constantes, representa um perigo aos demais, ou se encontra segregado, seja por razões próprias ou por outras da coletividade. Ora, as estatísticas mostram que, na França, um em cada dez franceses, se nos limitarmos à inadaptação social, e um a cada cinco, se a esses se juntarmos também pessoas com debilidades psíquicas ou mentais, fazem parte dessa “outra França”. (p. 10, tradução livre e grifos nossos).

Essa percepção moral da pobreza, herdeira da dupla tradição do século XIX, da higiene e da assistência social, inspira a forma de tratamento do Estado-providência de caráter liberal, ou seja, vencer a pobreza sem enfrentar as desigualdades (Stoléru, L. 1977, apud Fassin, 1996, p. 43).

A heterogeneidade das situações englobadas pela noção de exclusão na França induziu a contundentes críticas, de dupla natureza: (i) o caráter impreciso dessa noção, que englobava, numa mesma categoria, indivíduos com situações sociais bastante distintas e heterogêneas, como as que se referem aos portadores de deficiências físicas e mentais, bandidos ou indivíduos em posições sociais desfavoráveis, como a dos desempregados ou aqueles com dificuldades de aprendizagem escolar, como os jovens imigrantes; (ii) a dificuldade de separar fatores morais e socioculturais das condições objetivas de desigualdade e pobreza econômica.

Assim, na década de oitenta e noventa, dois tipos de contribuições analíticas desenvolveram um esforço para definir novos sentidos da noção de exclusão. A primeira abordagem, de caráter mais

${ }^{12}$ A construção desses argumentos iniciais da exclusão se dá na década de setenta, nos relatórios do Plan (Lanoir, 1974), em termos dos sistemas de ajudas sociais. 
analítico, procurou delimitar a população segundo campos simbólicos polares, demarcados a partir de quatro unidades de análise: a cidade (segmentação e fronteiras de convivência): ${ }^{13}$ a escola (a norma escolar), ${ }^{14} \mathrm{o}$ emprego (o contrato do trabalho); e a proteção social (a seguridade ou a assistência). ${ }^{15} \mathrm{~A}$ segunda abordagem reconhece no desemprego o determinante central dessas questões, reforçando a responsabilidade do poder público no encaminhamento de alternativas para a nova questão social. ${ }^{16}$ Em ambos os esforços, a sociedade é representada por uma imagem de fratura social, separando os que têm um "lugar" daqueles que precisam aí inserir-se. A produção sociológica francesa dos anos noventa vai refletir, fundamentalmente, os termos da "nova questão social”, marcada exatamente pela precarização do trabalho e pelo desemprego de longa duração e contra os riscos de fraturas sociais que ameaçam o convívio social.

As imagens da exclusão - expressas nas noções de "desqualificação social” (Paugam, 1991), "desfiliação" (Castel, 1995), divisão entre os "úteis" e os "normais inúteis" (Donzelot e Estèbe, 1991) e "empobrecimento" (Salama e Valier,1995) - constituem alguns esforços analíticos da literatura sociológica francesa para expressar esses processos de transição problemática da nova questão social.

Pierre Rosanvallon, no livro La nouvelle question sociale. Répenser l'Etat-providence (1995), reconhece a especificidade da fratura social dos anos oitenta, porque as mudanças contemporâneas alteram os princípios da solidariedade sobre os quais o Estado-providência francês se estruturou. Robert Castel, na Métamorphose de la question sociale (1995), recompõe historicamente a relação entre trabalho e sociabilidade, mostran-

${ }^{13}$ Ver, a propósito, Pinçon-Charlot M., Prétéceille e Rendu P., 1986; Grafmeyer, 1996; Labens, 1996; Oberti, 1996, Préteceille, E, 1999 a e b, 2003, entre outros.

14 Ver Dubet, François, 1991; Pinçon-Charlot, M. e Rendu, P. ,1988; van Zanten, A, 1990, Langouet, G. e Leger, A, 1991; Dubet e Lapeyronnie, 1992; van Zanten, A., Payet, J-P e Roullaeau-Berger, 1994; van Zanten, A. 1996.

${ }^{15}$ Nessa linha, ver especialmente os trabalhos de Paugam, 1991, 1996; Donzelot, 1994; Castel, 1995; Thomas, 1997.

${ }^{16}$ Cf. Donzelot, 1994; Castel, 1995 e Rosanvallon, 1995, por exemplo. do como a coesão social se construiu a partir da inserção dos indivíduos na divisão social do trabalho e revelando um processo de formação de uma zona de vulnerabilidade, reveladora da desconstituição (negativa) dessa relação. Criticando a perspectiva estática da noção de exclusão, Castel propõe, alternativamente, a noção de "desfiliação", de forma a recuperar a dimensão de processo na formação da vulnerabilidade dos indivíduos no mundo do trabalho e nas redes de sociabilidade. Numa crítica à dimensão estática definidora dos estados de exclusão e pobreza, ele diz:

A exclusão é estática. Ela designa mais um estado ou talvez estados de privação. Mas a constatação das situações de carência não permite reapreender os processos que geram essas situações. [...] Falar de desfiliação, ao contrário, não é ratificar uma ruptura, mas reconstituir um percurso. (p. 13-15, tradução livre).

\section{E, adiante:}

A exclusão não é ausência de relação social, mas um conjunto de relações sociais particulares à sociedade tomada como um todo. Não existem pessoas fora da sociedade, mas um conjunto de posições cujas relações com seu centro são cada vez mais distendidas. [...] E do centro que parte a onda de choque que atravessa a estrutura social. (p. 442-443, ibidem).

A articulação das perspectivas da precarização e segregação sobre o espaço urbano começa a ser problematizada, na França, desde a década de oitenta, a partir dos grandes conjuntos populares observados como "espaços problemáticos" (les quartiers difficiles ou sensibles). As críticas a essa segregação são de dupla natureza: de um lado, o reconhecimento de que essas periferias acabaram por não se integrar plenamente "na" cidade. De outro, o entendimento de que esses espaços cristalizaram uma nova problemática social, com a convergência de altas taxas de desemprego e dificuldades de integração dos trabalhadores imigrantes no âmbito da escolaridade e também do trabalho, comprometendo a coesão social.

O processo de diferenciação social do território amplia as desigualdades e contribui para estigmatizar grupos sociais e étnicos concentrados 
espacialmente, dos quais os demais grupos sociais buscam distanciar-se. Nesse processo, a questão escolar parece fundamental pela tendência das escolas de se diferenciarem muito segundo o perfil dos bairros. As dimensões territoriais das desigualdades, e sua percepção, acabam por fragilizar a coesão social, tal como ela foi construída na França do pós-guerra. (Lagrange e Oberti, 2006, p. 33, tradução livre).

Desse modo, não se pode analisar a questão das periferias urbanas sem levar em conta as relações que esses cidadãos têm no âmbito do trabalho e suas novas formas sociais. Da mesma forma que não se podem desconsiderar as responsabilidades do poder público sobre as condições de reprodução das camadas populares (ou os efeitos perversos de sua ausência). Focalizando-se apenas na dimensão espacial e vicinal, tende-se a não perceber os impactos imbricados da precarização do trabalho nesses universos territorializados e em suas redes sociais da precarização social, como nos falam Hirata e Préteceille (2002) . Num sentido inverso, não é possível entender-se a dinâmica dos processos de vulnerabilidade social sem associálos ao âmbito das práticas onde se tecem as experiências cotidianas de solidariedades no âmbito dos espaços da família, dos laços de sociabilidade primária e do consumo social.

Fassin (1996), apoiando-se na recuperação histórica feita por Michael Katz (1993), recompõe a evolução da noção de underclass na literatura americana. O autor descreve essa categoria como um conjunto de pessoas de difícil trato, hostis, com valores distintos da maioria dos pobres. Trata-se de uma "proporção extraordinariamente elevada de jovens em situação de insucesso escolar, delinquentes drogados, de mães assistidas”, diz ele (p. 48).

A primeira aparição da palavra underclass ocorre em 1962, no livro Challenge to affluence, do sueco Gunnar Myrdal, que a descreve como resultante de fatores ligados ao desemprego estrutural. Ele define esse termo como a categoria econômica dos mais desfavorecidos e com menor mobilidade social devido ao desemprego estrutural. Para ele, essa pobreza tende a perenizar-se e reproduzir-se ainda mais pelo efeito das discriminações a que essas populações são submetidas.
Essa visão estrutural dos liberais da década de sessenta ${ }^{17}$ vai ser substituída por uma visão mais conservadora, que não mais considera os determinantes estruturais da pobreza, entendendo essa classe como uma categoria moral, resultante de comportamentos individuais desviantes (behavioral deficiencies).${ }^{18} \mathrm{O}$ diagnóstico da questão social é individualizado sobre "os indivíduos e suas condutas”, e não sobre as condições de estruturação da sociedade em suas desigualdades. A investigação desenvolvida por Ken Auletta (1981), por exemplo, identifica quatro categorias desses pobres, classificadas a partir de características comportamentais e do tipo de vínculo institucional:

“os pobres passivos (passive poor), assistidos ge-
ralmente de longa data; os criminosos de rua
(street criminals), que amedrontam a maior parte
das cidades e estão normalmente excluídos do
sistema escolar e drogados; os escroques (hustlers)
que, como os criminosos de rua, também podem
não ser pobres e ganham a vida na economia
subterrânea (ilícita), mas raramente cometem
atos violentos; os vagabundos das cidades,
traumatizados, alcoólicos, perdidos, sem mora-
dia, doentes mentais que perambulam nas ruas
da cidade.” (Auletta, 1981, apud Fassin, tradu-
ção livre,1996)

Essa visão moral da pobreza não é nova e, desde o século XIX, as instituições caritativas dividiam os pobres em "meritórios" e os "não meritórios", estes que, na versão mais moderna, constituem a underclass. O que é novo, segundo Fassin (1996), é que os não meritórios do século XX compõem-se, na sua maioria, da população negra, de origem rural, à qual se associaram traços estigmatizantes, característicos de certa "cultura da pobreza”, como passividade, irresponsabilidade, instabilidade e dependência.

Um dos estudos típicos dessa visão moral da pobreza é o de Oscar Lewis "The culture of

\footnotetext{
${ }^{17} \mathrm{Na}$ década de sessenta, outros autores também fazem referência à noção de underclss. Entre eles, Michael Harrington, no livro The other American, 1962 e outros: Tom Kahn The economics of equility, 1964; Joan Gordon The poor of Harlem: social functioning in the underclass; Leonard Lieberman. Atomism and mobility among the underclass Chippewas and Whites, 1973 (Fassin, 1996).

${ }^{18}$ Uma análise sobre a evolução da própria noção de underclass e os contextos da política social nos Estados Unidos consta de Kowarick, 2003. Ler também: Wilson, 1987 e Peterson, 1991.
} 
poverty” (1966), um exemplo paradigmático das supostas características atribuídas aos pobres: o espírito gregário, o alcoolismo, o uso frequente da violência na regulação de conflitos, o uso da força e de castigos para a educação infantil, a iniciação precoce da vida sexual, a união livre ou o casamento consanguíneo, o frequente abandono da esposa e dos filhos pelo marido, uma tendência ao matriarcado, maiores vínculos com membros da família materna, uma forte disposição para o autoritarismo, a ênfase na solidariedade familiar, a falta de perspectivas de longo prazo, um sentido de resignação e um fatalismo fundados sobre as realidades de sua existência, a crença na superioridade masculina e as consequências dessa visão em relação à mulher, um complexo de mártir, e, enfim, uma tolerância maior com todos os casos de psicopatia. Essa imagem influenciou trabalhos de psicologia social, mas também de criminologia, nos meios populares marginais do terceiro mundo.

Assim, a problemática da pobreza, da cidade e das relações étnicas encontram-se estreitamente articuladas na caracterização da questão social e urbana do final do século XX, nos EEUU. Enquanto, nos anos sessenta, a underclass era entendida como o conjunto de indivíduos excluídos dos processos produtivos ou do trabalho, na década de oitenta, passam a representar, ao mesmo tempo, a decadência econômica, a segregação urbana e a discriminação racial como atributos de insucesso "pessoal". É a responsabilização individual dos processos sociais da pobreza.

Um exemplo da visão conservadora do welfare americano é o livro Losing ground. American social policy 1950-1980, de Charles Murrey (1984), ao analisar a política social americana. Esse autor considera que, apesar dos louváveis esforços da "revolução generosa" na luta contra a pobreza, a situação dos pobres nos EEUU piorou. ${ }^{19}$ Essa deterioração não é um epifenômeno, mas, segundo Murrey, "uma consequência direta

${ }^{19}$ Ele se refere à política declarada por Lindon Johnson da War on Poverty, em 1964. As críticas a essa política reconhecem que os seus resultados em relação à redução da pobreza foram reduzidos, mas foi importante como mecanismo de envolver negros e outras minorias nos processos políticos locais. (Cf Peterson, 1991).
[...] dos modelos de interpretação da pobreza construídos pela inteligentzia”. Ele considera que "quando os intelectuais não separaram os 'pobres responsáveis' daqueles 'menos responsáveis' acabaram por produzir uma política injusta, que toma dos primeiros (os responsáveis e meritórios) para dar aos segundos (os não meritórios). Trata-se, de fato, de uma política de 'transferência de pobres a pobres”' (p. 219 e 199). Assentado numa noção central de responsabilidade individual dos pobres sobre o seu destino, ele considera aceitável apenas a ajuda do Estado àqueles que perderam sua capacidade de trabalho.

Mais tarde, nos anos noventa, William Wilson, no livro The truley disavantaged. The inner city, the underclass and public policy (1987), critica explicitamente essa visão conservadora de Murrey, reabrindo o debate sobre a necessidade de uma abordagem mais sociológica e menos jornalística, buscando, agora, a gênese da underclass e suas causas. Wilson simplesmente rejeita o termo underclass, porque essa noção não expressa uma situação de classe homogênea e não tem fundamento teórico. Ele também reconhece que a abordagem comportamental desenvolvida por Murray, especialmente em relação aos negros nos guetos, colabora para uma visão discriminatória e para a ideologia de culpabilização da vítima (blaming victim), que pode aprofundar o racismo. Considera também que a visão restrita ao comportamento dos negros restringe muito a variável racial como determinante para a explicação dos fenômenos sociais. Para Wilson, superar essas associações supõe desenvolver estudos que deem conta da complexidade das situações de pobreza e suas determinações sociais, tendência que vai marcar as preocupações acadêmicas na década de noventa. Nesse período, a questão da subclasse (underclass) se impôs no debate político em torno das polêmicas alternativas de deslocamento das políticas sociais do welfare para o workfare, pelo qual os beneficiários estariam obrigados a realizar tarefas como condição de acesso aos benefícios, o que gera inúmeras polêmicas pelo retorno a formas indignas de trabalho forçado. 
Analisando-se ambas as noções, a de exclusion (na França) e a de underclass (nos Estados Unidos), observamos que a única relação possível entre ambas é o fato de se imporem ao mundo social e político como o "problema social do mundo urbano", apesar de não constituírem uma única e mesma problemática. A única similitude em torno desses dois temas, segundo Fassin (1996, p. 65), é que sua presença, em ambos os contextos, apresenta-se como ameaça aos princípios que organizam o mundo social urbano.

Esses milhões de pobres, marginais, squatters, mal-alojados, proletários cujo número não para de crescer constituem pouco a pouco um antimundo cujas frustrações e desesperanças alimentam naturalmente a violência nas fronteiras da sociedade estabelecida. (p.64-65)

Ora, dada a indeterminação dessas noções, Paul Peterson (1991) considera que elas podem ser usadas indistintamente por conservadores, liberais ou radicais. Mas essas representações do mundo não podem ser apenas práticas cognitivas. Elas se constituem também em ato político. Assim, Peterson mostra que o termo underclass é tanto adequado aos conservadores, quando querem identificar indivíduos incapazes de se assumirem ou com tendência a comportamentos antissociais, como a noção pode ser adequada para identificar um grupo subordinado às forças econômicas e políticas da sociedade, a exemplo do conceito de lumpemproletariado, além de também aceito de forma ambígua por liberais que se recusam a escolher entre os dois pontos de vista (Cf. Peterson, 1991). Mesmo considerando a articulação entre pobreza, segregação e etnicidade como elementos centrais na formulação da questão urbana contemporânea, tanto na França como nos Estados Unidos, Loïc Wacquant (1992) adverte sobre os riscos de se assimilar a situação das cités da periferia francesa aos ghettos negros americanos. É preciso cautela nas generalizações que falam de uma "americanização" da Europa ou da América Latina, ou num evolucionismo às avessas de certa visão de terceiro-mundista da Europa, tendo em vista a crescente informalização das relações de trabalho nes- se último continente. A consolidação da república, nessas sociedades, a centralidade do papel do Estado francês frente ao objetivo da integração nacional, os níveis de desenvolvimento dessas sociedades não podem considerar a emergência desses processos apenas sobre sua aparência formal. Nesses países de capitalismo avançado, o principal problema das cidades é desenvolver novas atividades econômicas e formas de integração social alternativas ao estatuto salarial que já não se constitui num mecanismo garantido de inserção. No entanto, as distintas tradições da cultura política, nesses países, conformam diferentemente a formulação da questão social, com consequências e limites dos novos dispositivos de integração social, inclusive sobre as instâncias locais.

\section{O GLOBAL E O LOCAL E A RECONVERSÃo DA QUESTÃO SOCIAL}

As grandes transformações que envolveram mudanças institucionais no papel dos Estados nacionais recolocaram também a importância da dimensão espacial desses processos - através das relações entre a dinâmica da globalização (desterritorialização) e localização, entre espaços de fluxos e espaços de lugares, o futuro das cidades e o novo papel das grandes metrópoles (Veltz, 1996; Harvey, 1989; Castells, 1996; Sassen, 1991). Esses processos globais parecem questionar as hierarquias urbanas e as relações entre territórios tal como esses foram concebidos até os anos setenta, como também a relação entre o espaço urbano e seus habitantes, entre o público e o privado, nas novas formas de constituição das atividades de morar, trabalhar, circular, consumir e de lazer.

Do lado da questão social, a perspectiva liberal, nesse novo contexto, parte do suposto de que é impossível a preservação das regras que orientavam a política social no marco do Estado de Bem-Estar Social, dada a crise fiscal, a excessiva intervenção do Estado no mercado e os possíveis estímulos negativos que os dispositivos institucionais geram no âmbito do comportamen- 
to dos indivíduos, alimentando, supostamente, comportamentos morais indesejáveis, como um possível parasitismo dos trabalhadores à custa do esforço das coletividades. Assim, a única via de retomada do crescimento e da economia consistiria, segundo a visão liberal, em romper a articulação entre "emprego e proteção social", sacrificando o "social”: a proteção social, a política de salário mínimo, etc.

O desenho da nova política social, no contexto da hegemonia neoliberal, pressupõe, portanto, a distensão da relação entre proteção social e emprego, rompendo o modelo que caracterizou as políticas redistributivas do Estado social. O centro dessa mudança situa-se, de um lado, na ruptura da proteção através das reformas da Previdência, afetando os direitos dos trabalhadores protegidos, e, de outro, na reorientação de programas estratégicos e compensatórios da assistência focalizada na linha da pobreza, segundo diferentes "públicos-alvo". No eixo desse dilema, observa-se a reconversão da "questão social", de uma dimensão de política de proteção, voltada para a produção da justiça social, para centrar-se sobre seus efeitos, através de programas mitigadores, setorializados e focalizados da pobreza. Opera-se, portanto, uma ruptura estrutural entre os planos social, econômico e político, através de um processo de transição que prioriza o tratamento da questão social com base em um novo modelo de assistência focalizado, centrado na seletividade em torno de políticas contra a discriminação e a diferença (étnica; mulheres; de geração; etc.).

Sposati (1998) ressalta duas dimensões que envolvem a ênfase na noção de exclusão social ao final do século XX: a denúncia da ruptura da noção de responsabilidade social e pública, que se construiu a partir da Segunda Guerra, e a quebra da universalidade da cidadania conquistada no Primeiro Mundo. A autora acrescenta que os movimentos sociais das minorias, nesses países, vêm sendo marcados por lutas pelo direito à diferença. Assim, "a noção de igualdade só se completa em contrapartida à noção de equidade. Dessa perspectiva não basta um padrão equânime se este não comportar o direito à diferença. Não se trata mais de um padrão universal, mas de um padrão equânime." (ibidem, 1998).

Os dilemas políticos que emergem das "novas regulações" políticas e sociais, no final do século XX e início do século XXI, num desenho de focalização das políticas, respondem a esses imperativos e têm, no âmbito local e nas solidariedades restritas, novas bases para as mediações sociais que se projetam hoje num futuro incerto e na busca de "novas formas de proteção". No caso brasileiro, esse patamar de universalidade não foi consagrado. Diferentemente da situação da França, a cultura patrimonialista divide a sociedade entre proprietários e elites, entre esses e a "ralé" (Sposati, 1998). A autora acrescenta que "o acesso à cobertura dos serviços sociais públicos é considerado, no país, uma manifestação de miserabilidade [...] não se trata apenas de acesso aos serviços de assistência social [...], mas dos próprios serviços de saúde e educação. Ademais, a exclusão no país não é residual, mas uma condição que atinge a grande maioria de brasileiros."

Do lado das responsabilidades institucionais no nível local, há de se pensar que a implementação das políticas sociais nas municipalidades supõe avanços institucionais, ou seja, municípios com capacidade de gerenciamento e geração de renda, condição nem sempre compatível com a realidade preexistente, a exemplo do que se conhece da maioria dos municípios brasileiros, e, de outro, de um papel de participação da sociedade civil nos programas. Nesse caso, são conhecidas as acomodações do Estado com as oligarquias locais, e as características oligárquicas da cultura política brasileira. Nesse sentido, muitos desses paradigmas encontram seus limites nos elementos que Nunes (1997) considera como a gramática política do Brasil: (i) o caráter patrimonialista e autoritário do Estado, e a consequente fragilidade das estruturas locais, influenciadas pelas relações clientelistas; (ii) a centralização dos dispositivos institucionais de modernização do aparelho do Estado brasileiro via formação de círculos burocráticos do planejamento, no controle da política; (iii) o compromisso 
corporativista do Estado populista nacional. Esses fatores, associados ao volume e à magnitude do processo de pobreza estrutural, e o padrão elevado das desigualdades tornam a operacionalização das políticas sociais, no âmbito das grandes cidades, particularmente complexo.

Na Europa, o município e as cidades começam a ser vistos como atores políticos, com novas responsabilidades para a gestão local das crises (Cf. Harvey, 1989). As questões sociais da cidade convertem-se, gradativamente, em questões de descentralização, competência de governos locais, melhoramentos de bairros, melhoria da imagem urbana, programas de melhoramento ou de privatização, substituindo-se ao planejamento em larga escala, que marcou as intervenções da década de sessenta e setenta.

Nos Estados Unidos, onde o modelo do Estado protetor nunca alcançou a mesma penetração, a questão não é a mesma. As políticas públicas do discurso neoconservardor de Reagan não consistiam em afrontar os novos problemas sociais e urbanos através do setor público, mas facilitar a reestruturação econômica através da flexibilização dos mercados de trabalho, o investimento privado em novas tecnologias e a renovação física das cidades através de coalizões ou "máquinas” orientadas para o crescimento. A expressão urbana desse processo foi a renovação de espaços tradicionais em áreas destinadas ao turismo e ao consumo sofisticado de novas classes e elites (Cf. Duhau, 2001, p. 45-46).

A contrapartida dessa dinâmica, como mostra Duhau, foi a presença ostensiva dos excluídos (underclass), desclassificados, produtos simultâneos da perda do emprego, do abandono dos aparatos da assistência do poder público, através do não-financiamento desses serviços, das áreas centrais de moradia popular, bem como a liberação de doentes mentais dos hospitais públicos. Prolifera, então, a "outra face" da paisagem urbana estadunidense: os homeless, bad-ladies, etc., de um lado, e o elemento do "medo" como constitutivo da experiência da sociabilidade urbana, ampliando as políticas de segurança urbana que tendem a "limpar" os espaços públicos, conforme analisa Loïc Wacquant em Les Prisions de la misère, 1999.

A experiência mais recente de redemocratização brasileira, confrontada à reconversão das novas regulações institucionais e de ajuste do Estado, mostram um conjunto de paradoxos que se expressam como tensões na inserção social da cidadania. O acesso aos direitos sociais e a vivência democrática ocorrem num contexto de reestruturação da economia, no qual os ajustes fiscais e a reestruturação produtiva têm por efeito a exclusão de um importante contingente de trabalhadores, o que se expressa tanto na perda de direitos ao trabalho (o desemprego) como na vivência antecipada da exclusão pela restrição dos postos de trabalho, especialmente pelos jovens. Assim, a exclusão do trabalho não se materializa apenas na dimensão da perda, mas se projeta na desesperança das novas gerações de trabalhadores, pela ausência de projeto de futuro, configurando uma "exclusão da inserção", restringindo a dinâmica da mobilidade social e desqualificando os tradicionais mecanismos de coesão e mobilidade social.

No plano institucional e político, as transformações não foram suficientes para compreender como os cidadãos podiam e podem enfrentar as novas tarefas do poder conquistado. A questão aqui não é de crise de representação, mas de desconexão entre o aparelho da ação pública e a sociedade. $\mathrm{O}$ que se discute agora é a impotência do Estado, a sua incapacidade para lutar contra o crescimento do desemprego, a segregação da periferia, a nova pobreza, e a dualização da sociedade, através da produção de políticas públicas estruturais. ${ }^{20}$

Nesse quadro de fraturas sociais, de desconexão entre os níveis econômico, político e social, é cada vez mais difícil dar um sentido efetivo de responsabilidades mais amplas e compartilhadas à cidadania moradora dessas periferias, já que ele não pode ser traduzido em condições reais, o que nas sociedades constitui a manifestação efetiva da inserção, que é o acesso ao trabalho, a garantia de formas de acesso ao consumo coletivo ${ }^{20}$ Cf. Donzelot, J. ( 1994) 
e o exercício na prática da justiça social. Essas dificuldades geram fraturas no pacto civil e desengajamentos morais, com efeito sobre as representações que os atores individuais fazem da democracia, da solidariedade, da cooperação, além de reforço à anomia, com o crescimento da violência. A questão social passa a deslocar-se, então, da questão da proteção social, do seguro social, para uma questão de proteção civil, da ordem e da segurança pública. Há, pois, um novo espaço de conflito de representações sobre a própria democracia, a nova questão social, sobre a qual se estrutura o novo conflito urbano na ordem pública.

Resumindo, pode-se afirmar que, no processo histórico de países com altos índices de desigualdade, como é o caso das cidades latino-americanas, a questão situa-se em torno de algumas tensões, entre as quais uma dissociação entre o econômico, o político e o social, o que tem efeito sobre os significados da política, definindo limites ou possibilidades do sistema de representações políticas e sociais, da própria democracia e, portanto, das possibilidades reais de construção do compartilhamento da vida social. ${ }^{21}$ Elas indicam, ainda, que a crise de legitimidade é a maior do nosso tempo, atingindo não somente o Estado, mas o conjunto das instituições sociais e políticas.

\section{O QUESTIONAMENTO DO ESTADO EDA SOCIEDADE PELO TERRITÓRIO: a formação da "sociedade incivil"22}

Sintetizando as dimensões de exclusão social desde o início de século XIX, essa noção de exclusão é reforçada pela associação de dois processos: de um lado, a perda do patamar de bemestar alcançado nos trinta gloriosos anos de prevalência de pleno emprego e direitos sociais

${ }^{21}$ Esse processo foi analisado, do ponto de vista de governabilidade e de crise de legitimidade, originalmente em Ivo (2001).

${ }^{22}$ A ideia de sociedade incivil é tomada de Lagrange e Oberti (2006) a respeito das movimentações de jovens no território francês, entre fins de 2005 e começo de 2006, de forma simultânea em vários bairros de periferia das cidades francesas, em novembro de 2005. ampliados, e, de outro, a perda da responsabilidade pública e social. Portanto, esse questionamento do "urbano" pelo "social", nas grandes cidades, parece assumir sua face mais crítica nas diversas explosões de violência urbana nas periferias das grandes cidades, como foi o caso dos motins de Los Angeles, em 1992, e das chamadas emeutes parisienses, de novembro de 2005, e de São Paulo, em maio de 2006, além dos diversos conflitos que se expressam no cotidiano das grandes cidades latino-americanas.

Multiplicam-se noticias e debates em torno da violência urbana, da falta de expectativas dos jovens, do desemprego, do aumento da pobreza e da precariedade, ao mesmo tempo em que se estimulam e compartilham, inversamente, espaços de consumo de massa modernos. Essa vivência controvertida entre pobreza e falta de expectativas de inserção no trabalho, para os jovens das grandes cidades brasileiras, e $\mathrm{o}$ apelo ao consumo moderno de massa, aprofundam as fraturas urbanas, pela impossibilidade de convivência e participação em condições de igualdade nos espaços públicos compartilhados. Gradativamente, o “social”, recolocado como questão resultante das mudanças no âmbito do trabalho e pelas reformas do Estado social (dos sistemas de proteção social), vai centralizar o debate sobre as cidades, indagando-se como encaminhar essa nova questão "social" com base na experiência do "lugar", nas cidades, daqueles (indivíduos e bairros) que exigem prioridade da ação pública.

Entre as lutas urbanas da década de oitenta e os motins da década de 2000, no entanto, parece haver uma enorme distância, seja pelo caráter de "classe" dos primeiros, resultado da organização e subjetividade de atores sociais com projetos políticos claros, seja, inversamente, pelas razões e formas de expressão dos atuais, em todos os países, de confrontação com o Estado e a sociedade. Donzelot (1999), referindo-se a essas diferenças para a França, mostrou que os primeiros colocaram esses atores urbanos no âmbito da esfera pública da sociedade civil, enquanto a forma do conflito urbano contemporâneo promove, no espaço público urbano, a "sociedade incivil". 
A violência dessas manifestações questiona o "lugar", ou melhor, o "não-lugar" dos cidadãos da periferia no espaço público da cidade. O "nãolugar" dessa periferia urbana passa a se constituir num “problema social”, especialmente nos países desenvolvidos, com repúblicas consolidadas, pela perda ou ausência da responsabilidade pública e pelos processos subsequentes de discriminação e segregação.

As análises de Lagrange e Oberti (2006) entendem que as manifestações de rua em novembro de 2005, na França, revelam

... certos limites de um modelo de integração de caráter universalista, fundado numa comunidade de cidadãos formalmente iguais, mas, na realidade, submetidos a tratamentos desiguais, especialmente sobre a base de uma lógica de segregação urbana e de discriminação misturadas a características sociais e étnico-raciais. (p. 33, tradução livre).

Relacionando os conflitos urbanos de novembro de 2005 (émeutes) com os de março e abril de $2006^{23}$, eles acrescentam:

As respostas dadas à crise social e urbana pretendiam continuar fieis a uma tradição estatal republicana, cujo objetivo de mixidade e de regulação pública e institucional permanecem centrais. Entretanto, instaurando medidas que acentuam a precariedade dos jovens, [a CPE] sob o pretexto de favorecer o emprego, eles fizeram explodir uma revolta que se apoia sobre valores universalistas. (p. 33-34, tradução livre).

Contrariamente às várias manifestações de violência urbana nos Estados Unidos e na GrãBretanha, na França não houve um afrontamento entre "etnias" ou "comunidades". As violências não visaram a grupos étnicos ou minorias específicas. Os jovens envolvidos nas manifestações se dirigiam ao poder público, tanto no nível nacional como no local. Incendiando escolas, ginásios, carros, questionavam as autoridades públicas, e não os interesses privados de grupos ou comunidades particulares. Não se pode, portanto, considerar essas manifestações como de caráter étnico, mesmo reconhecendo que, em alguns bairros, a maio-

${ }^{23}$ Em razão do CPE - Contrat de Premier Embauche (Contrato de Primeiro Emprego). ria dos jovens envolvidos eram imigrantes de origem magrebina, turca ou africana.

Em que pese o caráter de contestação frente ao poder público, Lagrange e Oberti (2006: 208/ 209) concluem ser difícil inscrever esses movimentos (especialmente o de novembro de 2005) num registro político. Não por falta de sentido político, mas porque tal sentido não foi traduzido dessa forma pelos demais, fora dos jovens atores e entre eles mesmos.

\section{E concluem:}

...o fato de essas émeutes não encontrarem lugar político ou mesmo associativo caracteriza os limites da capacidade da sociedade [francesa] de realizar sua inclusão política. As instituições hesitam em reconhecer as minorias como tais, e essa desconsideracão acentua ainda mais essas assimetrias. Situados no coração dos debates, os membros das minorias não existem no plano político.

Concluindo, a resposta, hoje, não se refere, portanto, a viabilizar exclusivamente as trocas mercantis, mas à capacidade política de a "cidade" produzir "sociedade", ou seja, diz respeito aos termos e às condições das trocas sociais na partilha do espaço urbano, e isso não se limita apenas a públicos mais ou menos segmentados.

(Recebido para publicação em fevereiro de 2010) (Aceito em abril de 2010)

\section{REFERÊNCIAS}

ARON, R. Les désillusions du progrès. Essai sur la dialectique de la modernité. Paris: Calmann-Lévy, 1969.

AULETTA, K. The underclass. New York: Rondom House, 1982.

BRESCIANI, Maria Stella. Cidade e História. In: Oliveira, Lúcia L. (Org.) Cidade: História e desafios. Rio de Janeiro: FGV Editora, 2002. p. 16-35.

CASTELLS, Manuel. La question urbaine. Paris: École Pratique des Hautes Études, 1972. Versão em português: A Questão Urbana. São Paulo: Paz e Terra, 2000.

Terra, 2006 .

A sociedade em rede. $9^{\text {a }}$ edição. S. Paulo: Paz e

CASTEL, Robert. Les métamorphoses de la question sociale. Une chronique du salariat. Paris: Fayard, 1995.

DONZELOT, Jacques. L'invention du social. Essai sur le déclin des passions politiques. Paris: Ed. Seuil, 1994. 
; ESTÈBE, P. L'État animateur: essai sur la politique de la ville. Paris: Editions Esprit, 1994.

La nouvelle question urbaine. Esprit. [Dossiê: Quant la ville se défait], p. 87-114, nov. 1999.

DUBET, François. Les Lycéens.Paris : Seuil, 1991.

; LAPEYRONNIE, D. Les quartiers d'exil. Paris: Seuil, 1992

DUHAU, E.; GIROLA, L. La ciudad y la modernidad inconclusa. Sociológica, ano 5, n. 12, 1992.

. Las metrópolis latinoamericanas en el siglo XXI. Cadernos IPPUR, v. XV, nº1, p. 41-68, jan./jul., 2001.

FASSIN, Didier. Exclusion, underclass, marginalidad. Figures, contemporaines de la pauvrété urbaine en France, aux États Unis et en Amérique. Révue Française de Sociologie, XXXVII, p. 37-75,1996.

GORDON, Joan. The poor of Harlem: social functioning in the underclas. New York: Office of the mayor, 1962.

GRAFMEYER, Yves. La ségrégation spaciale. In: PAUGAM, S. (Org.) L'exclusion: l'état de savoir. Paris: Ed. La Découverte/Coll. textes à l'́appui, 1996. p. 209-217.

HARRINGTON, M. The other American . New York: MacMillan, 1962 (Trad. francesa: L'autre Amérique. Paris: Gallimard, 1967).

HARVEY, David. A Condição da Pós-modernidade. São Paulo: Edições Loyola, 1998.

HIRATA, Helena; PRÉTECEILLE, Edmond. Trabalho, exclusão e precarização socioeconômica: o debate das ciências sociais na França. Caderno CRH. Salvador: Edufba, v.15 n. 37, p. 47-80, jul.-dez. 2002.

IVO, Anete B.L. O Poder da Cidade. Limites da Governança Urbana. Salvador-Bahia: EDUFBa.,2000.

Metamorfoses da questão democrática: governabilidade e pobreza. Buenos Aires: CLACSO,2001.

The restrict social integration: the local governance facing the social inequalities in the Third World cities. In: Cities as social fabric: fragmentation and integration. CONFERENCE RC 21 ISA, Paris, junho 2005.

JENKS, C.; PETERSON, P. (Edt.) The urban underclass. Washington: The Brookings Institution, 1991.

KAHN, Tom. The economics of equility. New York: League for industrial democracy, 1964.

KATZ, Michael. The urban "underclass" as a metaphor of social transformation. In: KATZ, M. (Ed.) The "underclss" debate. Views from history. Princeton: Princeton University Press, 1993. p. 3-33.

KOWARICK, Lúcio. Sobre a vulnerabilidade socioeconômica e civil. Estados Unidos, França e Brasil. Revista Brasileira de Ciências Socais, v. 18, n. 51, p. 6185, fev. 2003.

LABBENS, Jean. Le quart monde des cités d'urgence. In: Paugam, S. ( Org.) L'exclusion: l'état de savoir. Paris: Ed. La Découverte/Coll. textes à l'appui, 1996. p. 228-247

LAGRANGE, Hugues e OBERTI (Org.) Émeutes urbaines et protestations. Une singularité française. Paris: Presses de Sciences Po, 2006 (Collection Nouveaux Débats, 6).

LANOIR, René. Les exclus. Un Français sur dix. Paris: Ed. Seuls, 1974.

LEFEBVRE, Henri. Le droit à la ville. Paris: Anthropos, 1968. . La production de l'espace. Paris: Anthropos, 1974. rial, 1980
Le GALÈS. Patrick. Du gouvernement des villes à la gouvernance urbaine. Révue Française de Science Politique. Paris, v. 45, n. 1, p. 57-94, 1995.

LEWIS, Oscar. The culture of poverty. Scientific American, 215, 4, p. 19-25, 1966.

LIEBERMAN, Leonard. Atomism and mobility among the underclass Chippewas and Whites. In: Human Organization, v. 32, n. 4, p. 337-347, 1973

LOJKINE, Jean. La politique urbaine dans la region lyonnaise, 1945-1972. Paris: Moulon, 1974.

MICRO ROBERT. Dictionnaire du français primordial. Paris, 1980.

MUNFORD, Lewis. The city on the history. Its origin, its transformation and its prospects. New York: Harcourt Brace Jovanovich, 1961.

MURREY, Charles. Losing ground. American social policy 1950-1980. New York: Basic Books, 1984.

MYRDAL, Gunnar. Challenge to affluence. New York: Pantheon Books, 1962.

NUNES, Edson. A gramática política do Brasil. Clientelismo e insulamento burocrático. Rio de Janeiro: Zahar Edts, 1997.

OBERTI, Marco. La relégation urbaine, regards européens. In: PAUGAM, Serge ( Org.), L'Exclusion: l'état de savoirs. Paris: Ed. La Découverte/Coll. textes à l'appui, 1996. p. 237-247.

Homogénéiser ou différencier et spécialiser les contextes scolaires? In: LAGRANGE, Hugues e OBERTI, M. ( Org.) Émeutes urbaines et protestations. Une singularité française. Paris: Presses de Sciences Po., 2006. p. 147-176.

PAUGAM, Serge. La disqualification sociale. Essai sur la nouvelle pauvrété. Paris: Presses Universitaires de France/ Quadrige, 1991.

(Org.) L'Exclusion: l'état de savoirs. Paris: Ed. La Découverte/Coll. Textes à l'appui,1996.

PETERSON, Paul. The urban Underclass and the Poverty Paradox. In: JENKS, C. e PETERSON, P. (Edts.) The urban underclass. Washington:The Brookings Institution, 1991. p. 3- 27.

PINCSON-CHARLOT M.; PRÉTÉCEILLE, E.; RENDU. P. Ségrégation urbaine. Classes sociales et équipements collectifs en region parisienne. Anthropos. Paris, 1986.

PRÉTECEILLE, E. Inégalités Urbaines, Gouvernance, Domination? Reflexions sur l'agglomération parisienne. In: BALME, R, FAURE ET MALIBEAU (Orgs.) Les Nouvelles Politiques Locales. Dynamiques de l'action publique. Chap. II. Paris: Presses de Sciences Po., 1999. p. 57-76.

A evolução da segregação social das desigualdades urbanas. O caso da metrópole parisiense nas últimas décadas. Caderno CRH. Salvador: Edufba. v. 16, $\mathrm{n}^{\circ}$ 38, jan-jul, p. 27-48, 2003.

; RIBEIRO. Luiz César. Tendências da segregação social em metrópoles globais e desiguais: Paris e Rio de Janeiro nos anos 80. Revista Brasileira de Ciências Sociais, v. 14, n. 40, p. 143-162, junho 1999.

PUTNAM, Robert. Comunidade e Democracia. A experiência da Itália Moderna. Rio de Janeiro: Editora Fundação Getúlio Vargas, 1996.

ROSANVALLON, Pierre. La nouvelle question sociale. Répenser l'Etat-providence, Paris: Ed. Seuil,1995.

SALAMA P.; VALIER J. Mesures des pauvretés et de l' appauvrissement. Revue Tiers-Monde, v. 36 (142), AbrilJunho, 1995. 
SASSEN, Saskia. As Cidades na economia globalizada. S. Paulo: Ed. Nobel, 1998.

SENNET, Richard. The Fall of Public Man. $1^{\text {a }}$ edição 1977.New York:W.W.Norton \& Campany, 1992.Versão em português. $O$ declinio do homem público. São Paulo: Cia. Das Letras, 1988

SJOBERT, Gideon. The preindustrial city.Past and present. Glencoe, Illinoes: Free Press,1960.

SMITH, Adam et al. A riqueza das nações: investigação sobre sua natureza e suas causas. $1^{\text {a }}$ edição 1776 . Paulo: Nova Cultural, 1985

SPOSATI, Aldaíza. Exclusão social abaixo da linha do Equador. SEMINÁRIO EXCLUSÃO SOCIAL, PUC/S.P., 23 de abril de 1998.

STOLÉRU, L. Vaincre La pauvrété dans les pays riches. Paris: Flamarion, 1977.

TELLES, Vera e CABANES, R. (Orgs.) Nas tramas da cidade. Trajetórias Urbanas e seus territórios. S. Paulo: Associação Editorial Humanitas/ IRD, 2006.

THOMAS, Hélène. La production des exclus. Politiques sociales et processus de désocialisation scio-politique. Paris: Presses Universitaires de France. 1997.
WACQUANT, Loïc. Pour en finir avec le mythe, des 'citésghéttos'. Les différences entre la France et les États-Unis. Annales de la Recherche Urbaine, 54, p. 20-29, 1992.

Les Prisions de la misère. Paris : Éditions Raisons d'Agir, 1999.

WILSON, William. The truley disavantaged. The inner city, the underclass and public policy. Chicago: The University of Chicago Press, 1987.

WEBER, Max. La ville. Paris : Aubier Montaigne, 1982 [1947].

VELTZ, Pierre. Mondialisation, Villes et Territoires. L'économie d'archipel. Paris: Presse Universitaire de France, 1996.

van ZANTEN, Agnès. L'école et l'espace local. Les enjeux des zones d'éducation prioritaires. Lyon: Presses Universitaires de Lion, 1990.

; PAYET, J-P.; ROULLAEAU-BERGER, L. L'École dans la ville. Accords et désaccords autour d'un projet politique. Paris: l’Harmatann, 1994.

Fabrication et effets de la ségrégation scolaire. In: Paugam, S. (Org L'exclusion: I'état de savoir Paris: Ed. La Découverte/Coll. Textes à l’appui, 1996. p. 281-291. 


\section{THE URBAN ISSUE AND THE SOCIAL ISSUE: imperfect bonds}

Anete B. L. Ivo

This paper discusses the problematic relationship between urban issues and social issues, from classical studies to contemporary dilemmas. Drawing on French authors, this paper studies the crisis of the cities as an expression of acute contemporary social issue. It presents the
transition from conventional approaches of social class on the urban structure, that guided urban studies in the $60 \mathrm{~s}-70 \mathrm{~s}$, the deregulation of the nineties, which produced social processes of dissocialization, and the paradox of the managerial vision of the city, away from the dimension of redistribution of the welfare state. It examines the urban polarization through notions of exclusion, underclass and the suburbanization of cities and concludes by showing how territory questions the State and society through a culture of daily urban violence. Finally, it states that the challenge is not restricted to market relations, or to a political order, but concerns politics and the conditions the "city" has to produce "society."

KEYwORDS: urban issues, social issues, urban segregation, poverty, social conflicts.

\section{QUESTION SOCIALE ET QUESTION URBAINE: des liens imparfaits}

Anete B. L. Ivo

L'article analyse la relation problématique entre les questions urbaines et les questions sociales en allant des études classiques aux dilemmes contemporains. En se référant à des auteurs français, cet essai étudie la crise des villes en tant qu'expression aigue de la question sociale contemporaine. Il présente le passage aux approches classiques de classe sociale concernant la structuration urbaine qui ont guidé les études urbaines des années 60-70, la déréglementation des années quatre-vingt-dix qui a entrainé des processus de désocialisation sociale et le paradoxe de la vision managériale de la ville, éloigné de la dimension de redistribution de l'État social, y sont présentés. On y analyse la polarisation urbaine à travers des notions d'exclusion, d'underclass(sous-prolétariat) et de périphérisation des villes pour en arriver à la conclusion qui démontre comment le territoire remet en question l'État et la société par le biais d'une culture de violence urbaine quotidienne. Au final, on explique que le défi ne se limite pas aux relations marchandes, ou à une politique de l'ordre, mais concerne la politique et les conditions qu'a la ville de produire une "société".

Mots-CLÉs: question urbaine, question sociale, ségrégation urbaine, pauvreté, conflits sociaux.

Anete Brito Leal Ivo - Doutora em Sociologia pela UFPE. Atualmente é professora/pesquisadora da Universidade Católica do Salvador e do PPGCS/UFBA. Dirigiu inúmeras cooperações bilaterais com universidades francesas, tendo sido titular da Cátedra Simon Bolívar - Université de Paris III (2000) e professora convidada da Université de Paris XII (2006). É editora científica do Caderno CRH, desde 1996 e pesquisadora do Centro de Recursos Humanos da UFBA. É autora de artigos e livros de Sociologia, publicados no Brasil e no exterior nas temáticas: modernidade e questão social; pobreza, desigualdades e políticas sociais; Espaço público e ação coletiva, destacando-se os livros: Metamorfoses da questão democrática (B. Aires: CLACSO, 2001); Viver por um fio (Annablume, 2008); e The Transformation of the Social Issue.... em co-autoria com Ruthy Laniado. In: Ulrike Shuerkens (Org.). Globalization and trasnformation of social inequality (Londres/New York: Routledge, 2010). 
